\title{
Correction to: Postural orthostatic tachycardia syndrome (POTS) and other autonomic disorders after COVID-19 infection: a case series of 20 patients
}

\author{
Svetlana Blitshteyn ${ }^{1} \cdot$ Sera Whitelaw ${ }^{2}[$ \\ Published online: 13 April 2021 \\ ๑) Springer Science+Business Media, LLC, part of Springer Nature 2021
}

\section{Correction to: Immunologic Research}

https://doi.org/10.1007/s12026-021-09185-5

The published version of this article contained an error where the Abstract section was not captured by the publisher.

The original article has been corrected.

Publisher's note Springer Nature remains neutral with regard to jurisdictional claims in published maps and institutional affiliations.

The original article can be found online at https://doi.org/10.1007/ s12026-021-09185-5.

Svetlana Blitshteyn

sb25@buffalo.edu

1 Department of Neurology, State University of New York At Buffalo Jacobs School of Medicine and Biomedical Sciences, Buffalo, NY, USA

2 Department of Health Research Methods, Evidence and Impact, McMaster University, Hamilton, ON, Canada 